\title{
Lack of correlation between the antibody to hepatitis B core antigen and survival after surgical resection for hepatitis $\mathrm{C}$ virus-related hepatocellular carcinoma
}

\author{
HIROKI NISHIKAWA ${ }^{1}$, AKIRA ARIMOTO ${ }^{2}$, TOMOKO WAKASA ${ }^{3}$, \\ RYUICHI KITA $^{1}$, TORU KIMURA ${ }^{1}$ and YUKIO OSAKI ${ }^{1}$ \\ Departments of ${ }^{1}$ Gastroenterology and Hepatology, ${ }^{2}$ Surgery, and ${ }^{3}$ Pathology, \\ Osaka Red Cross Hospital, Tennoji-ku, Osaka 543-0027, Japan \\ Received February 1, 2013; Accepted March 16, 2013
}

DOI: $10.3892 / o r .2013 .2422$

\begin{abstract}
The impact of antibodies to hepatitis B core antigen (anti-HBc) on survival after curative surgical resection (SR) for hepatitis $\mathrm{C}$ virus (HCV)-related hepatocellular carcinoma (HCC) remains unclear. The aim of the present study was to examine the relationship between anti-HBc positivity and survival of HCV-related HCC patients who underwent curative SR. A total of 222 patients with HCV-related, hepatitis B surface antigen (HBsAg)-negative HCC who underwent curative SR were analyzed. They included 119 anti-HBcpositive patients $(53.6 \%)$ and 103 anti-HBc-negative patients (46.4\%). Overall survival (OS) and recurrence-free survival (RFS) rates were compared between the two groups. The median follow-up periods in the anti-HBc-positive and anti$\mathrm{HBc}-$ negative groups were 3.4 years (range, 0.3-10.9 years) and 3.2 years (range, 0.5-10.9 years), respectively. The 1-, 3- and 5-year cumulative OS rates were 88.8,70.2 and 50.0\%, respectively, in the anti-HBc-positive group and 95.8, 77.1 and $61.7 \%$ in the anti-HBc-negative group $(\mathrm{P}=0.300)$. The corresponding RFS rates were $68.7,33.0$ and $20.0 \%$, respectively, in the anti-HBc-positive group and 74.4, 38.5 and $16.5 \%$ in the anti-HBc-negative group $(\mathrm{P}=0.482)$. Multivariate analyses identified serum albumin $\geq 3.8 \mathrm{~g} / \mathrm{dl}(\mathrm{P}=0.005)$ and the presence of microvascular invasion $(\mathrm{P}<0.001)$ as independent factors linked to OS, and interferon therapy after surgery $(\mathrm{P}=0.011), \alpha$-fetoprotein $\geq 40 \mathrm{ng} / \mathrm{ml}(\mathrm{P}=0.030)$ and the presence of microvascular invasion $(\mathrm{P}<0.001)$ were significant predictors linked to RFS. In subgroup analyses according to maximum tumor size and background liver disease in terms
\end{abstract}

Correspondence to: Dr Hiroki Nishikawa, Department of Gastroenterology and Hepatology, Osaka Red Cross Hospital, 5-30 Fudegasaki-cho, Tennoji-ku, Osaka 543-0027, Japan

E-mail: h-nishikawa@osaka-med.jrc.or.jp

Key words: antibodies to hepatitis B core antigen, hepatitis $\mathrm{C}$ virus, hepatocellular carcinoma, surgery, overall survival, recurrence-free survival of OS and RFS, no significant difference between the anti$\mathrm{HBc}$-positive and anti-HBc-negative groups was observed except in patients with non-cirrhotic liver in terms of RFS. In conclusion, anti-HBc-positivity is not a useful predictor for survival of patients with $\mathrm{HCV}$-related $\mathrm{HCC}$ after curative SR.

\section{Introduction}

Hepatocellular carcinoma (HCC) is a major health problem worldwide. It is the fifth most common cancer in men and the seventh in women and the third most common cause of cancerrelated deaths (1-4). In Japan, as well as in other countries, most cases of $\mathrm{HCC}$ are associated with viral infections such as hepatitis B virus (HBV) and hepatitis C virus (HCV), although in our country, the number of HCC patients with etiologies other than HBV and HCV has recently been increasing $(2,5)$. In general, the prognosis for untreated $\mathrm{HCC}$ is poor, and the curative treatments consist of surgical resection (SR) and liver transplantation $(1,3,4)$. However, HCC frequently recurs after curative SR, leading to high mortality, although recurrence only occurs at intrahepatic sites in $68-96 \%$ of patients $(6,7)$. Stringent follow-up of HCC patients following SR is therefore essential.

Serum antibody to hepatitis B core antigen (anti-HBc) positivity, which indicates a past history of HBV infection, has recently been attracting attention as a predictor of liver carcinogenesis in patients with HCV-related liver diseases (8-12). HBV DNA may be present in a latent form, even after seroclearance of HB surface antigen ( $\mathrm{HBsAg}$ ), which is referred to as occult HBV infection $(8,13)$. Anti-HBc is reported to be a surrogate marker for such latent carriers (14). Moreover, previous studies have indicated that so-called occult HBV infection, reflected by anti-HBc positivity, is highly prevalent in a number of patient subgroups, including those with $\mathrm{HCV}$ infection and HCC, and may play an important role in hepatocarcinogenesis through expression of oncogenic viral protein $(10,15)$.

There have been several reports regarding the effect of anti$\mathrm{HBc}$ positivity on carcinogenesis in patients with $\mathrm{HCV}$-related liver disease, and most of these studies have reported that the presence of anti-HBc is a risk factor for the development of 
HCC in individuals with HCV infection $(8,10,15,16)$. However, it remains unknown whether anti-HBc positivity constitutes an additional risk factor in terms of survival after curative SR for HCV-related HCC. The aim of the present study was, therefore, to examine the relationship between anti-HBc positivity and survival in HCV-related HCC patients who underwent curative SR.

\section{Patients and methods}

Patients. Patients were selected for SR based on assessment of tumor characteristics, remnant liver volume, and general condition, through discussion with experienced surgeons, radiologists and physicians.

SR was performed on 405 treatment-naïve HCC patients at the Department of Surgery, Osaka Red Cross Hospital, Japan, between December 2001 and June 2012. There were $265 \mathrm{HCV}$-related HCC patients (64.7\%), negative for $\mathrm{HBsAg}$ and positive for the HCV antibody (HCVAb). Of these, we excluded patients operated on without curative intent $(n=24)$, with surgery-related death $(n=3)$ and those for whom antiHBc was not tested $(n=16)$. Curative surgery was defined as the resection of all tumors detectable using imaging modalities. A total of $222 \mathrm{HCV}$-related HCC patients were thus analyzed in the present study (Fig. 1). Patients were classified into two groups: anti-HBc-positive $(n=119,53.6 \%)$ and anti-HBc-negative $(n=103,46.4 \%)$. Overall survival (OS) and recurrence-free survival (RFS) rates were compared between the two groups.

All the protocols were approved by the Ethics Committee of our institution. Written informed consent was obtained from all patients prior to surgery, and the study protocol complied with all of the provisions of the Declaration of Helsinki. The present study comprised a retrospective analysis of patient records registered in our database and all treatments were conducted in an open-label manner.

HCC diagnosis. HCC was diagnosed using abdominal ultrasound and dynamic computed tomography (CT) scans (hyperattenuation during the arterial phase in all or some part of the tumor and hypoattenuation in the portal-venous phase) and/or magnetic resonance imaging (MRI), based mainly on the recommendations of the American Association for the Study of Liver Diseases (17). Arterial- and portal-phase dynamic CT images were obtained at $\sim 30$ and $120 \mathrm{sec}$, respectively, after the injection of the contrast material. HCC stage was determined using the Liver Cancer Study Group of Japan staging system (18). HCC was confirmed pathologically in specimens at surgery.

Serological studies. HBsAg and anti-HBc were detected using commercial enzyme immunoassay kits (Dainabot, Tokyo, Japan) (13). The results of the anti-HBc assays were expressed as the percentage of inhibition, and the specimens were considered to be anti-HBc-positive when the percentage of inhibition was $>50 \%$ (19). HCVAb was assessed using second-generation assays (Dainabot) (13). In the present study, serum HCV RNA levels were tested in $182(82.0 \%)$ out of 222 patients by using a competitive reverse transcription-polymerase chain reaction assay.

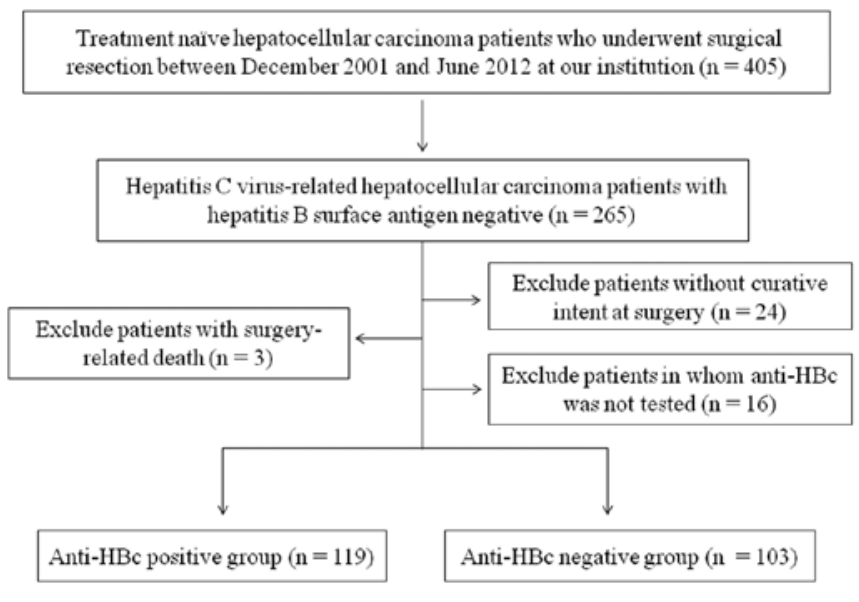

Figure 1. Study profile. Anti-HBc, antibody to hepatitis B core antigen.

Follow-up. Follow-up after surgery consisted of periodic blood tests and monitoring of tumor markers, including $\alpha$-fetoprotein (AFP) and des- $\gamma$-carboxy prothrombin (DCP), using chemiluminescent enzyme immunoassays (Lumipulse PIVKA-II Eisai; Eisai Co., Ltd., Tokyo, Japan). Dynamic CT scans and/or MRI were obtained every 2-4 months after surgery. Chest CT, whole abdominal CT, brain MRI, and bone scintigraphy were performed when extrahepatic HCC recurrence was suspected.

Statistical analysis. Data were analyzed using univariate and multivariate analyses. Continuous variables were compared using unpaired t-tests and categorical variables were compared using Fisher's exact tests. Time to recurrence was defined as the interval between each therapy and first confirmed recurrence. For analysis of RFS, follow-up ended at the time of first recurrence; other patients were censored at their last follow-up visit or the time of death from any cause without recurrence. For analysis of OS, follow-up ended at the time of death from any cause, and the remaining patients were censored at the last follow-up visit. The cumulative OS and RFS rates were calculated using the Kaplan-Meier method and tested using the log-rank test. Factors with a P-value $<0.05$ in univariate analysis were subjected to multivariate analysis using the Cox proportional hazards model. These statistical methods were used to estimate the interval from initial treatment. Data were analyzed using SPSS for Windows (SPSS Inc., Chicago, IL, USA). Data are expressed as means \pm standard deviation (SD). Values of $\mathrm{P}<0.05$ were considered to be statistically significant.

\section{Results}

Baseline characteristics. The baseline characteristics of the patients in the two groups are shown in Table I. The median observation periods were 3.4 years (range, 0.3-10.9 years) in the anti-HBc-positive group and 3.2 years (range, 0.5-10.9 years) in the anti-HBc-negative group. In terms of maximum tumor size $(\mathrm{P}=0.046)$, aspartate aminotransferase $(\mathrm{AST})$ value $(\mathrm{P}=0.027)$ and $\mathrm{DCP}$ value $(\mathrm{P}=0.046)$, significant differences were observed in the two groups. The proportion of HCC patients with cirrhotic liver in the anti-HBc-positive group tended to be higher than that in the anti-HBc-negative group $(\mathrm{P}=0.068)$. 
Table I. Baseline characteristics between the anti-HBc-postive group and the anti-HBc-negative group.

\begin{tabular}{|c|c|c|c|}
\hline Variables & $\begin{array}{l}\text { Anti-HBc positive group } \\
\qquad(\mathrm{n}=119)\end{array}$ & $\begin{array}{l}\text { Anti-HBc negative group } \\
\qquad(\mathrm{n}=103)\end{array}$ & P-value \\
\hline Age (years) & $69.3 \pm 8.1$ & $69.0 \pm 8.3$ & $0.798^{\mathrm{a}}$ \\
\hline Gender, male/female & $85 / 34$ & $66 / 37$ & $0.252^{\mathrm{b}}$ \\
\hline HCC Stage I/II/III/IVA & $12 / 70 / 27 / 10$ & $12 / 62 / 25 / 4$ & $0.590^{\mathrm{b}}$ \\
\hline Maximum tumor size (cm) & $4.3 \pm 2.8$ & $3.7 \pm 1.6$ & $0.046^{\mathrm{a}}$ \\
\hline Tumor number, single/multiple & $79 / 40$ & $74 / 29$ & $0.388^{\mathrm{b}}$ \\
\hline Background liver, cirrhotic/non-cirrhotic & $83 / 36$ & $59 / 44$ & $0.068^{\mathrm{b}}$ \\
\hline Hepatitis C viral load, high/low/unknown & $75 / 24 / 20$ & $69 / 14 / 20$ & $0.420^{\mathrm{b}}$ \\
\hline IFN therapy after surgery, yes/no & $11 / 108$ & $5 / 98$ & $0.299^{\mathrm{b}}$ \\
\hline AST (IU/l) & $71.5 \pm 41.4$ & $60.1 \pm 33.9$ & $0.027^{\mathrm{a}}$ \\
\hline ALT (IU/l) & $63.7 \pm 41.0$ & $57.6 \pm 44.3$ & $0.290^{\mathrm{a}}$ \\
\hline Serum albumin $(\mathrm{g} / \mathrm{dl})$ & $3.78 \pm 0.52$ & $3.78 \pm 0.48$ & $0.921^{\mathrm{a}}$ \\
\hline Total bilirubin (mg/dl) & $0.87 \pm 0.44$ & $0.82 \pm 0.40$ & $0.439^{\mathrm{a}}$ \\
\hline Prothrombin time $(\%)$ & $86.1 \pm 13.9$ & $88.9 \pm 12.8$ & $0.116^{\mathrm{a}}$ \\
\hline Platelets $\left(\mathrm{x} 10^{4} / \mathrm{mm}^{3}\right)$ & $13.1 \pm 6.1$ & $12.7 \pm 4.9$ & $0.569^{\mathrm{a}}$ \\
\hline $\operatorname{AFP}(\mathrm{ng} / \mathrm{ml})$ & $3,089.6 \pm 15,640.2$ & $789.2 \pm 2,708.3$ & $0.142^{\mathrm{a}}$ \\
\hline $\mathrm{DCP}(\mathrm{mAU} / \mathrm{ml})$ & $5,186.4 \pm 19,928.0$ & $1,207.2 \pm 2,845.3$ & $0.046^{\mathrm{a}}$ \\
\hline Diabetes mellitus, yes/no & $31 / 88$ & $32 / 71$ & $0.457^{\mathrm{b}}$ \\
\hline Body mass index $\left(\mathrm{kg} / \mathrm{m}^{2}\right)$ & $23.0 \pm 3.3$ & $23.1 \pm 4.1$ & $0.846^{\mathrm{a}}$ \\
\hline
\end{tabular}

Data are expressed as number or means \pm standard deviation. Anti-HBc, antibody to hepatitis B core antigen; HCC, hepatocellular carcinoma; IFN, interferon; AST, aspartate aminotransferase; ALT, alanine aminotransferase; AFP, $\alpha$-fetoprotein; DCP, des- $\gamma$-carboxy prothrombin . ${ }^{\mathrm{a}}$ Unpaired t-test; ${ }^{\mathrm{b}}$ Fisher's exact test.

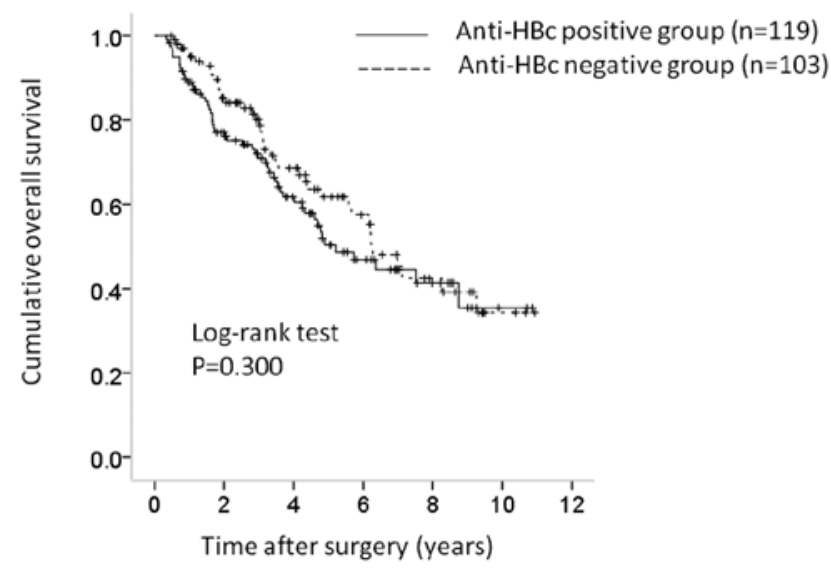

Figure 2. Cumulative overall survival (OS) rates between the anti-HBc-positive group $(n=119)$ and the anti-HBc-negative group $(n=103)$. The $1-, 3$ - and 5-year cumulative OS rates were $88.8,70.2$ and $50.0 \%$, respectively, in the anti-HBc-positive group and 95.8, 77.1 and $61.7 \%$ in the anti-HBc-negative group $(\mathrm{P}=0.300)$. Anti-HBc, antibody to hepatitis $\mathrm{B}$ core antigen.

Cumulative $O S$ and RFS rates. The 1-, 3- and 5-year cumulative OS rates were $88.8,70.2$ and $50.0 \%$, respectively, in the anti-HBc-positive group and 95.8, 77.1 and $61.7 \%$ in the antiHBc-negative group ( $\mathrm{P}=0.300)$ (Fig. 2). The corresponding RFS rates were $68.7,33.0$ and $20.0 \%$, respectively, in the anti-HBc-positive group and $74.4,38.5$ and $16.5 \%$ in the antiHBc-negative group ( $\mathrm{P}=0.482$ ) (Fig. 3).

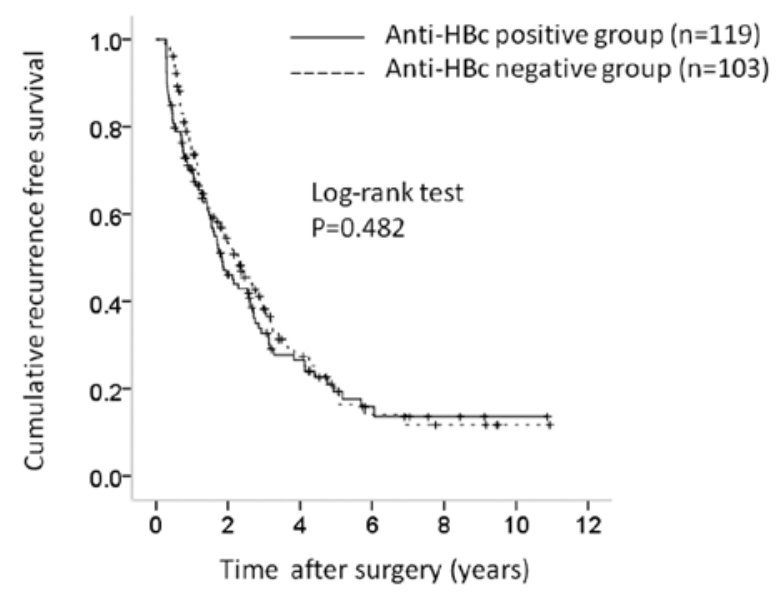

Figure 3. Cumulative recurrence-free survival (RFS) rates in the anti-HBcpositive group $(n=119)$ and the anti-HBc-negative group $(n=103)$. The $1-$, 3 - and 5-year cumulative RFS rates were $68.7,33.0$ and $20.0 \%$, respectively, in the anti-HBc-positive group and $74.4,38.5$ and $16.5 \%$ in the anti-HBcnegative group $(\mathrm{P}=0.482)$. Anti- $\mathrm{HBc}$, antibody to hepatitis $\mathrm{B}$ core antigen

Univariate and multivariate analyses of factors contributing to $O S$. Univariate analysis identified the following factors as significantly associated with OS for all cases $(n=222)$ : HCC stage $(\mathrm{P}<0.001)$; maximum tumor size $\geq 4 \mathrm{~cm} \quad(\mathrm{P}=0.016)$; tumor number $(\mathrm{P}=0.002)$; interferon $(\mathrm{IFN})$ therapy after surgery $(\mathrm{P}=0.044)$; serum albumin $\geq 3.8 \mathrm{~g} / \mathrm{dl} \quad(\mathrm{P}=0.023)$; 
Table II. Univariate analysis contributing to OS and RFS for all cases $(n=222)$.

\begin{tabular}{|c|c|c|c|}
\hline Variables & $\mathrm{n}$ & OS P-value & RFS P-value \\
\hline Age $\geq 70$ (yes/no) & $115 / 107$ & 0.120 & 0.957 \\
\hline Gender (male/female) & $151 / 71$ & 0.476 & 0.539 \\
\hline Background liver, cirrhotic/non-cirrhotic & $142 / 80$ & 0.748 & 0.233 \\
\hline Anti-HBc (positive/negative) & $119 / 103$ & 0.300 & 0.482 \\
\hline HCC stage (I, II/III, IV) & $156 / 66$ & $<0.001$ & $<0.001$ \\
\hline Maximum tumor size $\geq 4 \mathrm{~cm}(\mathrm{yes} / \mathrm{no})$ & $94 / 128$ & 0.016 & 0.023 \\
\hline Tumor number (single/multiple) & $69 / 153$ & 0.002 & $<0.001$ \\
\hline IFN therapy after surgery (yes/no) & $16 / 206$ & 0.044 & 0.019 \\
\hline ICG-R15 >14\% (yes/no) & $109 / 113$ & 0.288 & 0.864 \\
\hline Total bilirubin $\geq 1.0 \mathrm{mg} / \mathrm{dl}$ (yes/no) & $61 / 161$ & 0.068 & 0.022 \\
\hline Serum albumin $\geq 3.8 \mathrm{~g} / \mathrm{dl}$ (yes/no) & $124 / 98$ & 0.023 & 0.139 \\
\hline AST $\geq 60 \mathrm{IU} / 1$ (yes/no) & $103 / 119$ & 0.355 & 0.027 \\
\hline ALT $\geq 50$ IU/1 (yes/no) & $109 / 113$ & 0.393 & 0.008 \\
\hline Platelets $\geq 13 \times 10^{4} / \mathrm{mm}^{3}$ (yes $\left./ \mathrm{no}\right)$ & $103 / 119$ & 0.336 & 0.900 \\
\hline Prothrombin time $\geq 80 \%$ (yes/no) & $151 / 71$ & 0.771 & 0.351 \\
\hline $\mathrm{AFP} \geq 40$ ng/ml (yes/no) & $94 / 128$ & 0.085 & 0.001 \\
\hline $\mathrm{DCP} \geq 100$ mAU/ml (yes/no) & $130 / 92$ & 0.270 & 0.034 \\
\hline Microscopic capsule (yes/no) & $178 / 44$ & 0.833 & 0.412 \\
\hline Microscopic capsule invasion (yes/no) & $132 / 90$ & 0.188 & 0.390 \\
\hline Microscopic vascular invasion (yes/no) & $69 / 153$ & $<0.001$ & $<0.001$ \\
\hline Microscopic surgical margin (yes/no) & $28 / 194$ & 0.475 & 0.912 \\
\hline
\end{tabular}

OS, overall survival; RFS, recurrence-free survival; HCC, hepatocellular carcinoma; IFN, interferon; ICG-R15, indocyanine green retention at

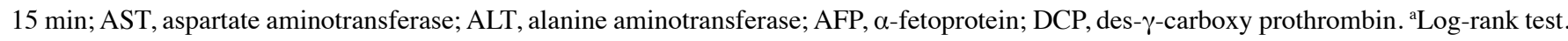

Table III. Multivariate analysis contributing to OS after surgical resection.

\begin{tabular}{|c|c|c|c|}
\hline Variable & Hazard ratio & $95 \%$ confidence interval & $\mathrm{P}$-value ${ }^{\mathrm{a}}$ \\
\hline \multicolumn{4}{|l|}{ HCC stage } \\
\hline I or II & 1.000 & & 0.347 \\
\hline III or IV & 0.621 & $0.230-1.674$ & \\
\hline \multicolumn{4}{|c|}{ Maximum tumor size $(\mathrm{cm})$} \\
\hline$\geq 4$ & 0.849 & $0.548-1.316$ & 0.465 \\
\hline$<4$ & 1.000 & & \\
\hline \multicolumn{4}{|l|}{ Tumor no. } \\
\hline Single & 1.000 & & \\
\hline Multiple & 0.855 & $0.322-2.279$ & 0.753 \\
\hline \multicolumn{4}{|c|}{ IFN therapy after surgery } \\
\hline Yes & 4.001 & $0.983-16.280$ & 0.053 \\
\hline No & 1.000 & & \\
\hline \multicolumn{4}{|c|}{ Serum albumin } \\
\hline$\geq 3.8 \mathrm{~g} / \mathrm{dl}$ & 1.841 & $1.205-2.812$ & 0.005 \\
\hline$<3.8 \mathrm{~g} / \mathrm{dl}$ & 1.000 & & \\
\hline \multicolumn{4}{|c|}{ Microscopic vascular invasion } \\
\hline Yes & 0.424 & $0.274-0.655$ & $<0.001$ \\
\hline No & 1.000 & & \\
\hline
\end{tabular}

OS, overall survival; HCC, hepatocellular carcinoma; IFN, interferon. ${ }^{\mathrm{a} C o x}$ proportional hazard model. 
Table IV. Multivariate analysis contributing to RFS after surgical resection.

\begin{tabular}{|c|c|c|c|}
\hline Variable & Hazard ratio & $95 \%$ confidence interval & P-value ${ }^{a}$ \\
\hline \multicolumn{4}{|l|}{ HCC stage } \\
\hline I or II & 1.000 & & \multirow[t]{2}{*}{0.245} \\
\hline III or IV & 0.659 & $0.326-1.331$ & \\
\hline \multicolumn{4}{|c|}{ Maximum tumor size (cm) } \\
\hline$\geq 4$ & 0.838 & $0.593-1.185$ & \multirow{2}{*}{0.318} \\
\hline$<4$ & 1.000 & & \\
\hline \multicolumn{4}{|c|}{ Tumor number } \\
\hline Single & 1.000 & & \multirow[t]{2}{*}{0.283} \\
\hline Multiple & 0.681 & $0.338-1.374$ & \\
\hline \multicolumn{4}{|c|}{ IFN therapy after surgery } \\
\hline Yes & 2.760 & $1.267-6.012$ & \multirow[t]{2}{*}{0.011} \\
\hline No & 1.000 & & \\
\hline \multicolumn{4}{|c|}{ Total bilirubin (mg/dl) } \\
\hline$\geq 1$ & 0.863 & $0.574-1.298$ & \multirow[t]{2}{*}{0.480} \\
\hline$<1$ & 1.000 & & \\
\hline \multicolumn{4}{|l|}{ AST (IU/l) } \\
\hline$\geq 60$ & 1.000 & & \multirow[t]{2}{*}{0.295} \\
\hline$<60$ & 1.291 & $0.800-2.085$ & \\
\hline \multicolumn{4}{|l|}{$\operatorname{ALT}(\mathrm{IU} / \mathrm{l})$} \\
\hline$\geq 50$ & 1.000 & & \multirow[t]{2}{*}{0.796} \\
\hline$<50$ & 0.942 & $0.600-1.479$ & \\
\hline \multicolumn{4}{|c|}{$\operatorname{AFP}(\mathrm{ng} / \mathrm{ml})$} \\
\hline$\geq 40$ & 0.678 & $0.478-0.962$ & \multirow[t]{2}{*}{0.030} \\
\hline$<40$ & 1.000 & & \\
\hline \multicolumn{4}{|c|}{$\mathrm{DCP}(\mathrm{mAU} / \mathrm{ml})$} \\
\hline$\geq 100$ & 1.000 & & \multirow[t]{2}{*}{0.128} \\
\hline$<100$ & 1.296 & $0.928-1.810$ & \\
\hline \multicolumn{4}{|c|}{ Microscopic vascular invasion } \\
\hline Yes & 0.480 & $0.335-0.689$ & \multirow[t]{2}{*}{$<0.001$} \\
\hline No & 1.000 & & \\
\hline
\end{tabular}

RFS, recurrence-free survival; HCC; hepatocellular carcinoma; IFN, interferon; AST, aspartate aminotransferase; ALT, alanine aminotransferase; AFP, $\alpha$-fetoprotein; DCP, des- $\gamma$-carboxy prothrombin; ${ }^{a}$ Cox proportional hazard model.

and microscopic vascular invasion $(\mathrm{P}<0.001)$ (Table II). The hazard ratios (HRs) and $95 \%$ confidence intervals (CIs) calculated using multivariate analysis for the 6 factors that were significant in univariate analysis are detailed in Table III. Serum albumin $\geq 3.8 \mathrm{~g} / \mathrm{dl}(\mathrm{P}=0.005)$ and microscopic vascular invasion $(\mathrm{P}<0.001)$ were found to be significant predictors linked to OS in multivariate analysis.

Univariate and multivariate analyses of factors contributing to RFS. Univariate analysis identified the following factors as significantly associated with RFS for all cases $(n=222)$ : HCC stage $(\mathrm{P}<0.001)$; maximum tumor size $\geq 4 \mathrm{~cm}(\mathrm{P}=0.023)$; tumor number $(\mathrm{P}<0.001)$; IFN therapy after surgery $(\mathrm{P}=0.019)$; total bilirubin $\geq 1.0 \mathrm{mg} / \mathrm{dl}(\mathrm{P}=0.022) ; \mathrm{AST} \geq 60 \mathrm{IU} / 1(\mathrm{P}=0.027)$; alanine aminotransferase $\geq 50 \mathrm{IU} / \mathrm{l}(\mathrm{P}=0.008) ; \mathrm{AFP} \geq 40 \mathrm{ng} / \mathrm{ml}$ $(\mathrm{P}=0.001)$; $\mathrm{DCP} \geq 100 \mathrm{mAU} / \mathrm{ml}(\mathrm{P}=0.034)$; and microscopic vascular invasion $(\mathrm{P}<0.001)$ (Table III). The HRs and $95 \%$ CIs calculated using multivariate analysis for the 10 factors that were significant in univariate analysis are detailed in Table IV. IFN therapy after surgery $(\mathrm{P}=0.011)$, AFP $\geq 40 \mathrm{ng} / \mathrm{ml}$ $(\mathrm{P}=0.030)$ and microscopic vascular invasion $(\mathrm{P}<0.001)$ were found to be significant prognostic factors linked to RFS.

Causes of death in the two groups. Fifty-two patients in the antiHBc-positive group (43.7\%) died during the follow-up period. The causes of death were HCC recurrence in 39 patients, liver failure in 9 and other causes in 4 . Forty patients in the anti$\mathrm{HBc}$-negative group (38.8\%) died during the follow-up period, and the causes of death were HCC recurrence in 25 patients, liver failure in 10 , and other causes in 5 .

$H C C$ recurrence. In the present study, 85 anti-HBc-positive patients $(71.4 \%)$ and 68 anti-HBc-negative patients $(66.0 \%)$ had HCC recurrence during the follow-up period. The patterns of $\mathrm{HCC}$ recurrence after surgery in the anti-HBc-positive group were: single HCC recurrence in the liver in 35 patients; 

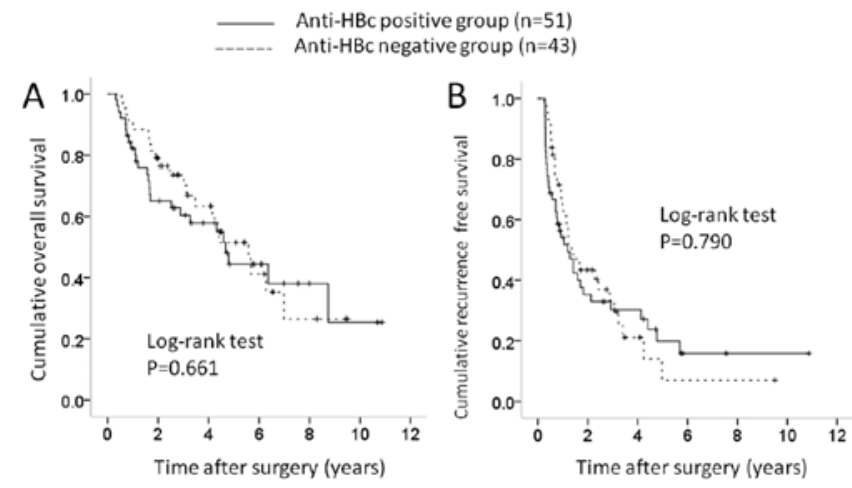

Figure 4. Subgroup analyses according to maximum tumor size. There were 51 patients with maximum tumor size $\geq 4 \mathrm{~cm}$ in the anti- $\mathrm{HBc}$-positive group and 43 in the anti-HBc-negative group. In terms of (A) overall survival $(\mathrm{P}=0.661)$ and $(\mathrm{B})$ recurrence-free survival $(\mathrm{P}=0.790)$, the differences in the two groups were not significant. Anti-HBc, antibody to hepatitis B core antigen.
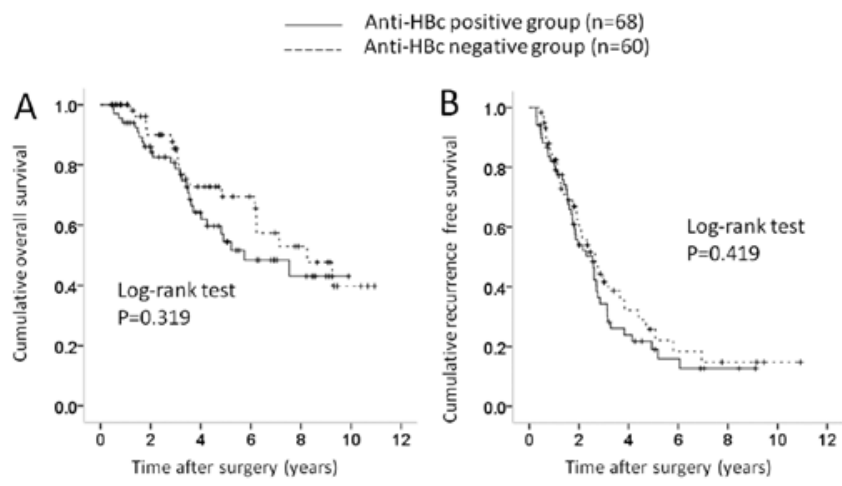

Figure 5. Subgroup analyses according to maximum tumor size. There were 68 patients with maximum tumor size $<4 \mathrm{~cm}$ in the anti-HBc-positive group and 60 in the anti-HBc-negative group. In terms of (A) overall survival $(\mathrm{P}=0.319)$ and $(\mathrm{B})$ recurrence-free survival $(\mathrm{P}=0.419)$, the differences in the two groups were not significant. Anti-HBc, antibody to hepatitis B core antigen..

multiple $\mathrm{HCC}$ recurrences in the liver in 42 patients; multiple $\mathrm{HCC}$ recurrences in the liver with lung metastases in 3 patients; multiple HCC recurrences in the liver with lymph node metastases in 2 patients; multiple HCC recurrences in the liver with peritoneal dissemination in 1 patient; multiple $\mathrm{HCC}$ recurrences in the liver with portal vein tumor invasion in 1 patient; and single brain metastasis in 1 patient. The patterns of $\mathrm{HCC}$ recurrence after surgery in the anti-HBc-negative group were: single $\mathrm{HCC}$ recurrence in the liver in 28 patients; single HCC recurrence in the liver with portal vein invasion in 1 patient; multiple HCC recurrences in the liver in 36 patients; multiple $\mathrm{HCC}$ recurrences in the liver with lymph node metastases in 1 patient; multiple $\mathrm{HCC}$ recurrences in the liver with inferior vena cava invasion in 1 patient; and multiple $\mathrm{HCC}$ recurrences in the liver with bone metastases in 1 patient.

Treatment methods for HCC recurrence. Treatment methods for the first $\mathrm{HCC}$ recurrence in the anti-HBc-positive group were: SR in 9 patients; radiofrequency ablation (RFA) in 35 ; transcatheter arterial chemoembolization (TACE) in 26; percutaneous ethanol injection (PEI) in 3; systemic chemo-

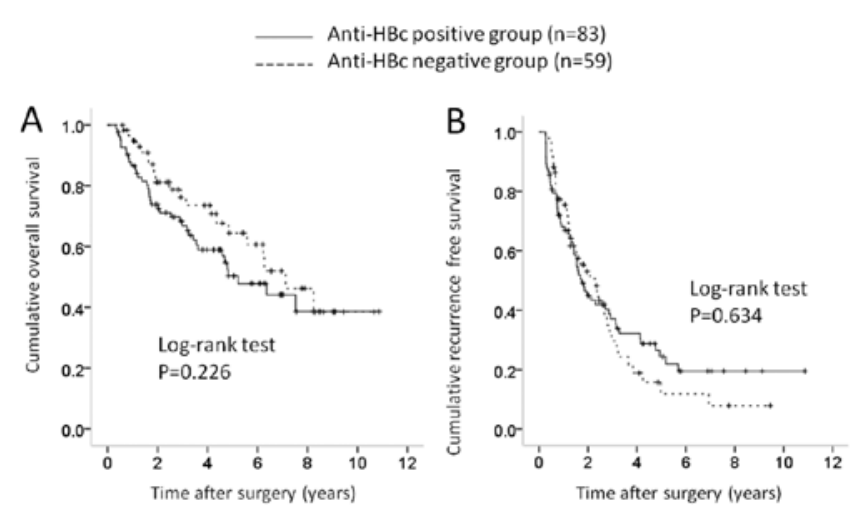

Figure 6. Subgroup analyses according to background liver disease. There were 83 patients in the anti-HBc-positive group with cirrhotic liver and 59 in the anti-HBc-negative group. In terms of $(\mathrm{A})$ overall survival $(\mathrm{P}=0.226)$ and (B) recurrence-free survival $(\mathrm{P}=0.634)$, there were no significant differences in the two groups. Anti-HBc, antibody to hepatitis B core antigen.

therapy in 3 ; radiotherapy in 1 ; and no specific treatment in 8 patients. The treatment methods used in the anti-HBc-negative group were: SR in 3 patients; RFA in 40; TACE in 20; PEI in 3; radiotherapy in 1 ; and no specific treatment in 1 patient.

IFN therapy after surgery. In the present study, 16 patients [11 patients (9.2\%) in the anti-HBc-positive group and 5 (4.9\%) in the anti-HBc-negative group] received IFN therapy after surgery. They included stage I HCC in 2 patients, stage II in 9 , stage III in 4 and stage IV in 1 . Whether IFN therapy after surgery was performed was mainly determined by decision of the attending physicians. Of these, all patients had high viral load as defined by the guidelines before IFN therapy $(20,21)$. Fourteen patients received peginterferon and ribavirin combination therapy and 2 received long-term low-dose IFN maintenance therapy. Seven patients $(43.8 \%)$ achieved sustained virological response as defined by undetectable HCV RNA 24 weeks after completion of IFN treatment. Seven patients $(43.8 \%)$ had HCC recurrence and 2 (12.5\%) died during the follow-up period.

Subgroup analyses according to maximum tumor size. In terms of maximum tumor size, there was a significant difference in baseline characteristics between the anti-HBc-positive and anti-HBc-negative groups. We therefore performed subgroup analyses according to maximum tumor size. In patients with maximum tumor size $\geq 4 \mathrm{~cm}$ [51 (42.9\%) in the anti-HBcpositive group and 43 (41.7\%) in the anti-HBc-negative group], no significant difference was observed in OS $(\mathrm{P}=0.661)$ and RFS ( $\mathrm{P}=0.790)$ (Fig. 4A and 4B). In patients with maximum tumor size $<4 \mathrm{~cm}$ [68 $(57.1 \%)$ in the anti-HBc-positive group and $60(58.3 \%)$ in the anti-HBc-negative group], there was no significant difference in OS $(\mathrm{P}=0.319)$ and RFS $(\mathrm{P}=0.419)$ (Fig. 5A and 5B).

Subgroup analyses according to background liver disease. Marginal significance was observed between the two groups in terms of background liver disease $(\mathrm{P}=0.068)$, and we therefore performed subgroup analyses accordingly. In patients with cirrhotic liver [83 (69.7\%) in the anti-HBc-positive group and $59(57.3 \%)$ in the anti-HBc-negative group], there was no 

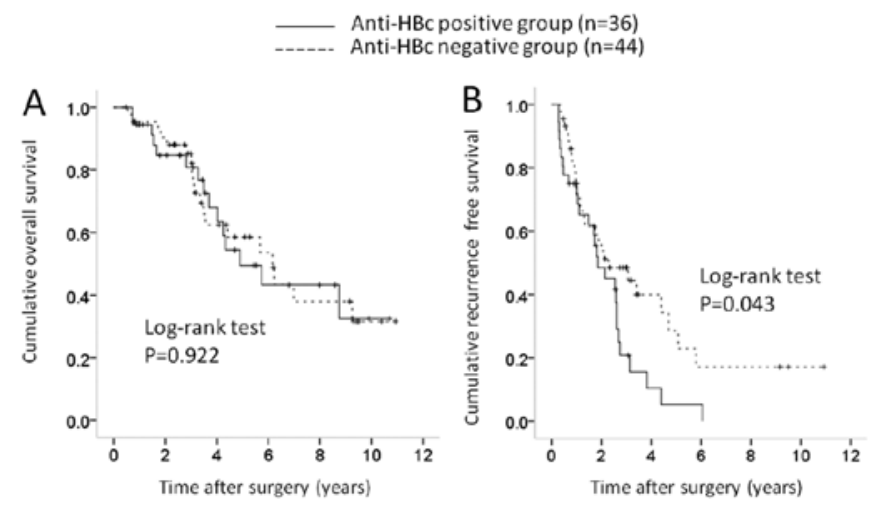

Figure 7. Subgroup analyses according to background liver disease. There were 36 patients with non-cirrhotic liver disease in the anti-HBc-positive group and 44 in the anti-HBc-negative group. In terms of (A) overall survival $(\mathrm{P}=0.922)$, there was no significant difference in the two groups, however, in terms of (B) recurrence-free survival, there was a significant difference $(\mathrm{P}=0.043)$. Anti-HBc, antibody to hepatitis B core antigen

significant difference in OS $(\mathrm{P}=0.226)$ and $\mathrm{RFS}(\mathrm{P}=0.634)$ (Fig. 6A and 6B). In patients with non-cirrhotic liver disease [36 $(30.3 \%)$ in the anti-HBc-positive group and $44(42.7 \%)$ in the anti-HBc-negative group], there was no significant difference in OS $(\mathrm{P}=0.922)$, whereas there was a significant difference in RFS ( $\mathrm{P}=0.043)$ (Fig. 7A and 7B).

\section{Discussion}

To the best of our knowledge, this is the first reported comparative study to examine the relationship between anti$\mathrm{HBc}$ positivity and survival in patients with $\mathrm{HCV}$-related $\mathrm{HCC}$ who underwent curative SR, although our study was retrospective in nature. Several previous studies have reported that anti-HBc positivity influences carcinogenesis in patients with HCV-related liver disease; however, as far as we are aware, there has been no report regarding the effect of anti-HBc positivity on survival after curative SR for HCC. Hence the reason for the present study.

In our analyses, anti-HBc positivity was not a significant factor in terms of OS and RFS. Moreover, in subgroup analyses according to maximum tumor size and background liver disease, RFS did not differ significantly in all subgroups except in patients with non-cirrhotic liver disease. These results suggest that anti-HBc positivity cannot be a useful predictor for patients with HCV-related HCC who undergo curative SR, although in those with non-cirrhotic liver disease, it may be associated with $\mathrm{HCC}$ recurrence after surgery.

There were 119 patients $(53.6 \%)$ with anti-HBc positivity in the present study. Marusawa et al (12) reported that 363 (59.4\%) out of $611 \mathrm{HCV}$-related HCC patients had anti-HBc positivity, and have suggested that $\mathrm{HBV}$ infection, including latent infection, plays an important role in carcinogenesis in patients with HCV-related liver disease. Our results were similar to that study, although in terms of HCC recurrence, anti-HBc positivity was not demonstrated to be a prognostic factor. In contrast, Mazzaferro et al (22) reported that 70 $(46.7 \%)$ out of 150 patients with HCV-related HCC were anti$\mathrm{HBc}$ positive, which was slightly lower than the result in our study. Racial and geographical factors may have been associated with these results.

In our study, the proportion of patients with cirrhotic liver in the anti-HBc-positive group tended to be higher than that in the anti-HBc-negative group. Several studies have demonstrated that the prevalence of anti-HBc positivity is closely correlated with the clinical stage of liver disease $(9,10,12)$. Our results were consistent with these reports, which suggest that anti-HBc should be closely monitored in patients with advanced $\mathrm{HCV}$-related liver disease.

The baseline AST level in the anti-HBc-positive group was significantly higher than that in the anti-HBc-negative group in our study. Although the reasons for this are unknown, in patients with $\mathrm{HCV}$-related to liver disease, anti-HBc positivity may correlate with higher activity of background liver disease.

HCC often recurs after curative surgery, leading to high mortality (6). Indeed, in the present study, 85 anti-HBcpositive patients $(71.4 \%)$ and 68 anti-HBc-negative patients (66.0\%) had HCC recurrence during the follow-up period. Stringent follow-up of HCC patients following SR is therefore essential. In the present study, microvascular invasion was the strongest prognostic factor in terms of both OS and RFS. In the postoperative management of HCC, preoperative factors such as degree of liver damage, radiological findings, and tumor markers as well as factors based on postoperative status should be considered (23).

In the present study, IFN therapy after surgery was a significant prognostic factor in terms of RFS, and was a marginally significant factor associated with OS, although the number of patients who received IFN therapy after surgery was small. Several investigators have reported that IFN therapy after curative SR in patients with HCV-related HCC improves clinical outcome (24-26). Our results are consistent with these reports; additional IFN therapy should be taken into account in patients with HCV-related HCC who undergo curative SR.

Serum albumin levels were significantly associated with OS in our multivariate analysis. Patients with liver cirrhosis and low serum albumin levels can develop protein-energy malnutrition with increased catabolism (27). Protein-energy malnutrition is associated with high morbidity and mortality because of an increased risk of life-threatening complications, resulting in poor survival and reduced quality of life (28). In the present study, 142 patients $(64.0 \%)$ had cirrhotic liver, indicating that a high proportion of patients with HCV-related HCC have concurrent liver cirrhosis. Branched chain amino acid treatment may optimize clinical outcome in these patients $(29,30)$.

There were several limitations to the present study. First, it was a single-center retrospective study. Second, the median observation periods in the two groups were relatively short for survival analysis. Third, patients in whom anti-HBc was not tested were excluded from our analysis, leading to bias. Larger prospective studies with longer observation periods are thus required to confirm these results. However, the current study demonstrated that anti-HBc positivity was not associated with survival in patients with HCV-related HCC who underwent curative surgery. In conclusion, anti-HBc positivity need not be taken into account when assessing clinical outcome in patients with HCV-related HCC after curative surgery. 


\section{Acknowledgements}

The authors would like to thank Haruko Takada for data collection.

\section{References}

1. Livraghi T, Mäkisalo H and Line PD: Treatment options in hepatocellular carcinoma today. Scand J Surg 100: 22-29, 2011.

2. El-Serag HB: Epidemiology of viral hepatitis and hepatocellular carcinoma. Gastroenterology 142: 1264-1273, 2012.

3. de Lope CR, Tremosini S, Forner A, et al: Management of HCC. J Hepatol 56 (Suppl 1): S75-S87, 2012.

4. El-Serag HB: Hepatocellular carcinoma. N Engl J Med 365 $1118-1127,2011$.

5. Umemura T and Kiyosawa K: Epidemiology of hepatocellular carcinoma in Japan. Hepatol Res 37 (Suppl 2): S95-S100, 2007.

6. Nishikawa H, Osaki Y, Kita R, et al: Transcatheter arterial infusion chemotherapy prior to radiofrequency thermal ablation for single hepatocellular carcinoma reduces the risk of intrahepatic distant recurrence. Int J Oncol 41: 903-909, 2012.

7. Zhou WP, Lai EC, Li AJ, et al: A prospective, randomized, controlled trial of preoperative transarterial chemoembolization for resectable large hepatocellular carcinoma. Ann Surg 249: 195-202, 2009

8. Ohki T, Tateishi R, Goto E, et al: Influence of anti-HBc seropositivity on the risk of hepatocellular carcinoma in HCV-infected patients after adjusting for confounding factors. J Viral Hepat 17: 91-97, 2010.

9. Squadrito G, Pollicino T, Cacciola I, et al: Occult hepatitis B virus infection is associated with the development of hepatocellular carcinoma in chronic hepatitis $\mathrm{C}$ patients. Cancer 106 1326-1330, 2006.

10. Ikeda K, Marusawa H, Osaki Y, et al: Antibody to hepatitis B core antigen and risk for hepatitis C-related hepatocellular carcinoma: a prospective study. Ann Intern Med 146: 649-656, 2007.

11. Lok AS, Everhart JE and Di Bisceglie AM; HALT-C Trial Group: Occult and previous hepatitis B virus infection are not associated with hepatocellular carcinoma in United States patients with chronic hepatitis C. Hepatology 54: 434-442, 2011.

12. Marusawa H, Osaki Y, Kimura T, et al: High prevalence of antihepatitis B virus serological markers in patients with hepatitis C virus related chronic liver disease in Japan. Gut 45: 284-288, 1999.

13. Shiota G, Oyama K, Udagawa A, et al: Occult hepatitis B virus infection in HBs antigen-negative hepatocellular carcinoma in a Japanese population: involvement of $\mathrm{HBx}$ and p53. J Med Virol 62: 151-158, 2000

14. Jilg W, Sieger E, Zachoval R and Schätzl H: Individuals with antibodies against hepatitis B core antigen as the only serological marker for hepatitis B infection: high percentage of carriers of hepatitis B and C virus. J Hepatol 23: 14-20, 1995.

15. Cacciola I, Pollicino T, Squadrito G, Cerenzia G, Orlando ME and Raimondo G: Occult hepatitis B virus infection in patients with chronic hepatitis C liver disease. N Engl J Med 341: 22-26, 1999.
16. Tanaka K, Nagao Y, Ide T, Kumashiro R and Sata M: Antibody to hepatitis $\mathrm{B}$ core antigen is associated with the development of hepatocellular carcinoma in hepatitis $C$ virus-infected persons: a 12-year prospective study. Int J Mol Med 17: 827-832, 2006.

17. Bruix J and Sherman M: Practice Guidelines Committee, American Association for the Study of Liver Diseases: Management of hepatocellular carcinoma. Hepatology 42: 1208-1236, 2005

18. Liver Cancer Study Group of Japan: The general rules for the clinical and pathological study of primary liver cancer. Jpn J Surg 19: 98-129, 1989.

19. Marusawa H, Uemoto S, Hijikata M, et al: Latent hepatitis B virus infection in healthy individuals with antibodies to hepatitis B core antigen. Hepatology 31: 488-495, 2000.

20. National Institutes of Health: Consensus Development Conference Statement. Management of hepatitis C: June 10-12, 2002. Hepatology 36 (Suppl 1): S3-S20, 2002.

21. Strader DB, Wright T, Thomas DL and Seeff LB; American Association for the Study of Liver Diseases: Diagnosis, management, and treatment of hepatitis C. Hepatology 39: 1147-1171, 2004.

22. Mazzaferro V, Romito R, Schiavo M; HCC Italian Task Force: Prevention of hepatocellular carcinoma recurrence with alphainterferon after liver resection in HCV cirrhosis. Hepatology 44: 1543-1554, 2006.

23. Lim KC, Chow PK, Allen JC, et al: Microvascular invasion is a better predictor of tumor recurrence and overall survival following surgical resection for hepatocellular carcinoma compared to the Milan criteria. Ann Surg 254: 108-113, 2011.

24. Sakae M, Kubo S, Takemura S, et al: Effect of interferon therapy on first and second recurrence after resection of hepatitis $C$ virus-related hepatocellular carcinoma. Hepatol Res 42: 564-573, 2012.

25. Tanimoto $\mathrm{Y}$, Tashiro $\mathrm{H}$, Aikata $\mathrm{H}$, et al: Impact of pegylated interferon therapy on outcomes of patients with hepatitis $\mathrm{C}$ virusrelated hepatocellular carcinoma after curative hepatic resection. Ann Surg Oncol 19: 418-425, 2012.

26. Singal AK, Freeman DH Jr and Anand BS: Meta-analysis: interferon improves outcomes following ablation or resection of hepatocellular carcinoma. Aliment Pharmacol Ther 32: 851-858, 2010.

27. Lautz HU, Selberg O, Körber J, Bürger M and Müller MJ: Protein-calorie malnutrition in liver cirrhosis. Clin Investig 70: 478-486, 1992.

28. Italian Multicentre Cooperative Project on Nutrition in Liver Cirrhosis: Nutritional status in cirrhosis. J Hepatology 21: 317-335, 1994.

29. Nishikawa H, Osaki Y, Inuzuka T, et al: Branched-chain amino acid treatment before transcatheter arterial chemoembolization for hepatocellular carcinoma. World J Gastroenterol 18: 1379-1384, 2012.

30. Nishikawa H, Osaki Y, Iguchi E, et al: The effect of long-term supplementation with branched-chain amino acid granules in patients with hepatitis $\mathrm{C}$ virus-related hepatocellular carcinoma after radiofrequency thermal ablation. J Clin Gastroenterol 47: 359-366, 2012. 